


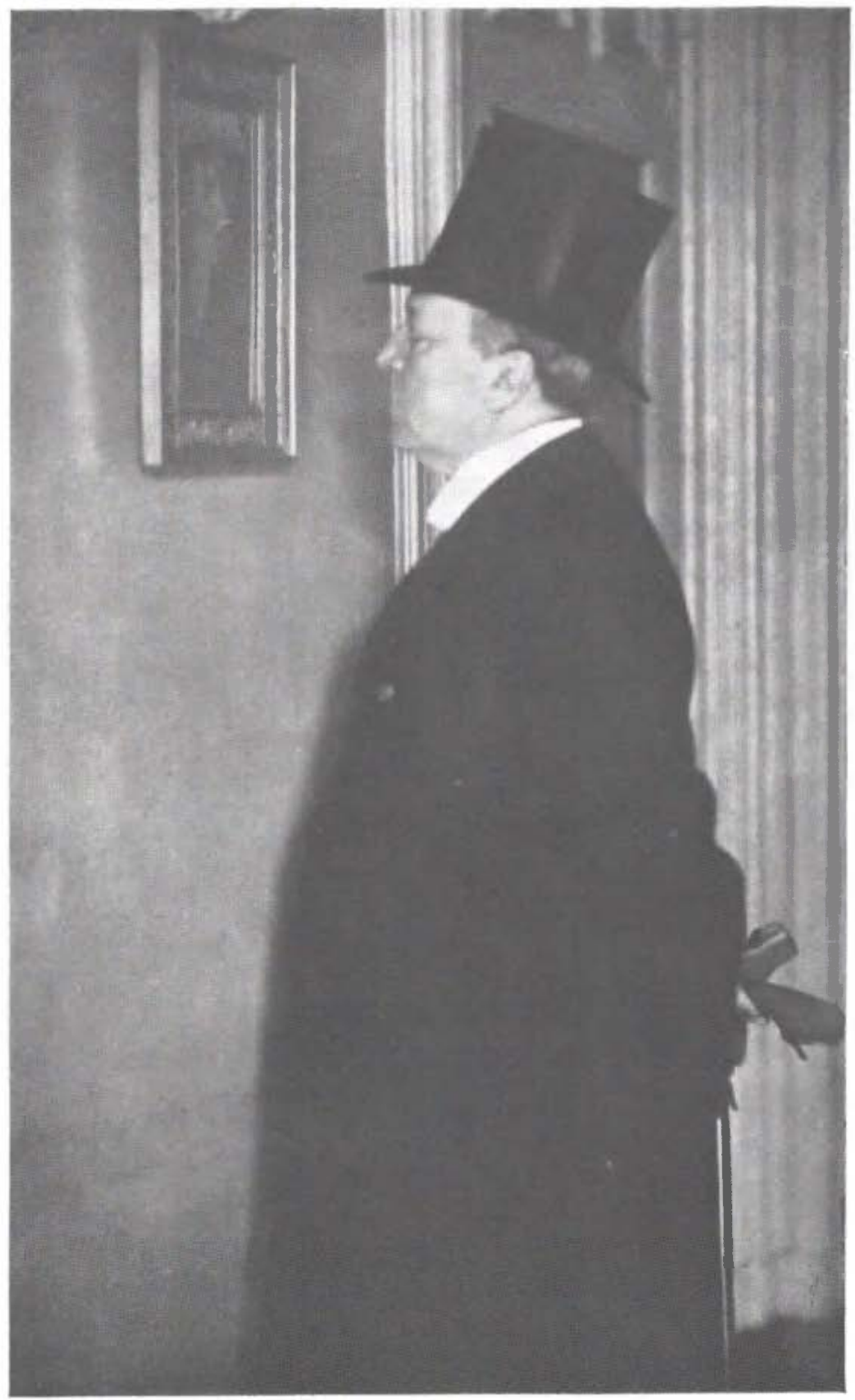

From a photograph by Alice Boughton 


\title{
The Painter's Eye
} NOTES AND ESSAYS ON THE PICTORIAL ARTS BY

\section{HENRY JAMES}

\author{
SELECTED AND EDITED \\ WITH AN INTRODUCTION BY \\ JOHN L. SWEENEY
}

HARVARD UNIVERSITY PRESS

CAMBRIDGE, MASSACHUSETTS

1956 
Copyright 1956 by The President and Fellows Harvard College

Printed in Great Britain by Robert MacLehose and Co. Ltd The University Press, Glasgow 